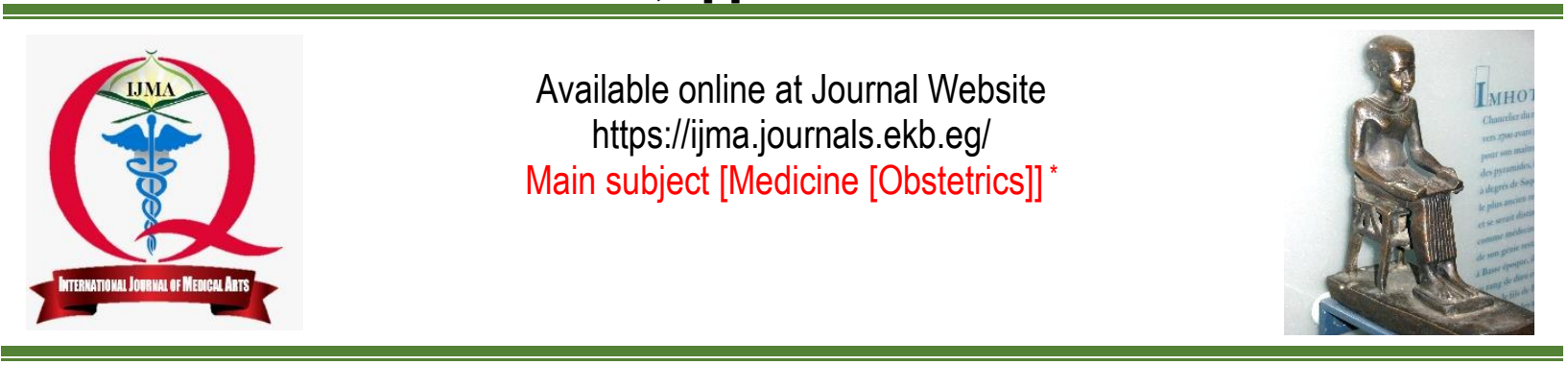

Original article

\title{
Office Hysteroscopy Versus Three-Dimensional Ultrasound in Assessment of Uterine Cavity in Recurrent Pregnancy Loss
}

\author{
Mohamed Atef Farag[a]; Mohamoud Salah Mahmoud [b]; Rashed Mohamed Rashed[b]
}

Department of Obstetrics and Gynecology, El-Mahalla General Hospital, Ministry of Health, Egypt [a]

Department of Obstetrics and Gynecology, Damietta Faculty of Medicine, Al-Azhar University, Egypt ${ }^{[b]}$

Corresponding author: Moahmed Atef Farag

Email: free.69310.free@gmail.com

Received at: March 18, 2020; Revised at: May 23, 2020; Accepted at: may 27, 2020; Available online at: May 27, 2020

DOI: 10.21608/ijma.2020.25674.1110

\begin{abstract}
Background: Recurrent pregnancy loss [RPL] is one of the most frustrating and difficult areas in reproductive medicine.

Aim of the work: This prospective study aims to evaluate the roles of ultrasound and hysteroscopy in recurrent pregnancy loss.

Patients and Methods: A total of 100 patients who had a history of two or more RPL had been included. All patients had been subjected to complete history taking, thorough clinical and gynecological examination, three-dimensional [3D] ultrasound and hysteroscopy.
\end{abstract}

Results: The mean age was 27.43 years. In addition, $45 \%$ of the included females had two previous RPL while $55 \%$ of them had three or more RPL. Hysteroscopy revealed normal findings in 80 cases [80\%], endometrial polyp in $7 \%$, submucous myoma in 3\%, uterine septum in 6\%, and uterine synechiae in $4 \%$. On the other side, three-dimensional ultrasound [3D US], normal findings had been detected in 83 cases [83\%], endometrial polyp in $6 \%$, submucous myoma in $3 \%$, uterine septum in $5 \%$, bicornuate uterus in $1 \%$, and uterine synechiae in $2 \%$. There was a statistically significant correlation between the two techniques in detection of the uterine findings in cases of RPL [ $p=0.001]$.

Conclusion: Three-dimensional ultrasonography is the best tool for diagnosis of different types of Mullerian duct anomalies whereas hysteroscopy is better in diagnosis of intracavitary lesions.

Keywords: Pregnancy loss; Three-D ultrasound; Hysteroscopy; Infertility; Evaluation.

This is an open access article under the Creative Commons license [CC BY] [https://creativecommons.org/licenses/by/2.0/]

Please cite this article as: Farag MA, Mahmoud SM, Rashed MR. Office Hysteroscopy Versus Three-Dimensional Ultrasound in Assessment of Uterine Cavity in Recurrent Pregnancy Loss. IJMA 2020; 2[3]: 542-546.

${ }^{*}$ Main subject and any subcategories have been classified according to research topic. 


\section{INTRODUCTION}

Recurrent pregnancy loss [RPL] represents one of the most challenging areas in obstetrics because the exact etiology is mostly unidentified and there are few evidence-based diagnostic and management strategies ${ }^{[1]}$. RPL classically refers to the occurrence of $\geq 3$ successive losses of clinically recognized pregnancies prior to the $20^{\text {th }}$ week of gestation [ectopic and molar pregnancies are not included] [2]. Most obstetricians identify RPL as $\geq 2$ failed pregnancies and recommend some evaluation subsequent to every loss with a thorough evaluation subsequent to $\geq 3$ losses ${ }^{[3]}$. Acquired and congenital uterine abnormalities are accountable for 10 to $50 \%$ of RPL. RPL could be associated with defective distention of the uterus or abnormal implantation because of reduced septum vascularity, severe inflammation, or low sensitivity to steroid hormones ${ }^{[4]}$. Hysteroscopy is regarded as the best tool for the intrauterine lesion diagnosis. In addition, a lot of these lesions can be managed during the procedure. However, it also could not dependably distinguish between a bicornuate and a septate uterus unless a laparoscopy to view the uterine fundus is also performed. hysteroscopic uterine assessment is usually reserved for patients who have had a nondiagnostic evaluation of RPL or those who had suspected intrauterine lesion is and operative hysteroscopy may be necessary [5].

Where available, hysteroscopy is perfect in diagnosis the anomalies of the uterus. In contrast to two-dimensional ultrasound, it allows visualization of both the cavity of the uterus and its outer surface [6].

\section{AIM OF THE WORK}

This study was conducted to compare threedimensional [3D] ultrasonography and hysteroscopy in the evaluation of recurrent pregnancy loss.

\section{PATIENTS AND METHODS}

This is a prospective study that included a total of 100 patients with a history of two or more recurrent pregnancy loss. The history of previous abortion was documented by a positive pregnancy test or the history of the expulsion of products of conception [in first-trimester abortion] or the expulsion of a fetus [in second-trimester abortion]. Conversely, cases with molar, ectopic pregnancy, or induced abortion were excluded from the current study.
All patients had been subjected to complete history taking, thorough physical examination, and routine clinical and gynecological examination. Three-dimensional ultrasound [US] had been performed by a single investigator after the patient had been instructed to empty her bladder. The uterus was scanned in the sagittal plane. Measurement of the double-layer endometrial thickness was done at the widest area between the endometrial-myometrial interfaces in the sagittal plane by using electronic calipers. Suspected uterine anomaly, the presence of a double cavity uterus, fibroid or polyp was recorded. Hysteroscopy was performed during the follicular phase of the cycle [between days 5 and 13]. The procedure had been carried out in an out-patient setting with anesthesia by an investigator who was blinded to the ultrasound findings. A 30-degree forward-oblique lens telescope and a $5 \mathrm{~mm}$ outer diameter rigid continuous flow hysteroscope [Tekno, $\mathrm{GmbH}$, Germany] had been used. In the presence of a narrow cervical canal, $400 \mu \mathrm{g}$ misoprostol [Cytotec $(200 \mu \mathrm{g}$ tablets, Pharmacia, Kent, UK] had been vaginally inserted two hours before the procedure. The 'no-touch' or vaginoscopic approach had been used which means that the scope was inserted to the vagina, cervical canal, and uterine cavity without using the speculum, tenaculum, analgesia, or anesthesia. When the external cervical os had been discovered, the scope had been passed through the cervical canal which was seen at 6 or 12 o'clock [anteverted or retroverted] respectively.

Normal saline was used to distend the uterine cavity for better visualization. The intrauterine cavity was inspected by rotation of the body of the scope by $90^{\circ}$ [right and left] for the examination of the tubal ostia, and then the scope had been pulled back at the level of the internal cervical os in order to get a panoramic view of the uterus. The presence of vaginal or cervical septa had been recorded.

The prevalence of anatomic uterine abnormalities had been determined, and the prevalence of such abnormalities had been compared between women with first and second-trimester RPL.

Ethical consideration: According to medical ethics, the steps of the work and the details of the procedures had been explained to all patients, and informed consent was gained from all included cases. The study was registered by code number: [IRB00012367-18-02-007]. 
Farag MA, et al.

Sample size:

The required sample size was calculated using the IBM $^{a}$ SPSS $^{a}$ SamplePower $^{a}$ version 3.0.1 $\left[\right.$ IBM $^{\mathrm{a}}$ Corp., Armonk, NY, USA]. Based on an intensive literature review, the incidence of uterine polyps in the study conducted by Midan et al. [2017][7] was $14 \%$. A total number of 96 cases was required to detect the expected incidence of 105At 95\% level of significance and power of $80 \%$.

\section{Statistical analysis}

Recorded data were analyzed using SPSS software, version 20.0 [SPSS Inc., Chicago, Illinois, USA]. Quantitative data were expressed as mean \pm standard deviation [SD]. Qualitative data were expressed as frequency and percentage. Chi-square [x2] test was performed to compare qualitative variables. $p$-value $<0.05$ was considered significant.

\section{RESULTS}

Table [1] shows that this study included 100 cases with recurrent pregnancy loss. The mean age of patient was $27.43 \pm 6.58$ years with a range between 18 and 40 years. The mean BMI of the included females was $24.18 \pm 4.27 \mathrm{~kg} / \mathrm{m}^{2}$ with a range between 21 and $36 \mathrm{~kg} / \mathrm{m}^{2}$. Table [2] shows that 45\% of the included females had two RPL while $55 \%$ of them had three or more RPL.

Table [3] shows that by hysteroscopy the following uterine findings were detected, normal in $80 \%$ of the cases, endometrial polyp in $7 \%$, submucous myoma in $3 \%$ of the cases, uterine septum in $6 \%$ of the cases and uterine synechia in $4 \%$ of the cases. By $3 \mathrm{D}$ ultrasound, the following uterine findings were detected, normal in $83 \%$ of the cases, endometrial polyp in 6\%, submucous myoma in $3 \%$ of the cases, uterine septum in $5 \%$ of the cases, bicornuate uterus in $1 \%$ and uterine synechia in $2 \%$ of the cases.

Table [4] shows that there was a statistically significant correlation between the two techniques in detecting the uterine findings in cases of RPL [kappa factor 0.895 and $p=0.001$ ]. Table [5] shows that the inter-method agreement between diagnosis by hysteroscopy and diagnosis by the 3D US in cases of $2 \mathrm{RPL}$ or cases with $\geq$ three RPL with no significant difference that indicates good agreement with better assessment associated with the use of 3D as it could detect anomalies that weren't detected by hysteroscopy such as the bicornuate uterus.

Table [1]: Patients characteristics of studied females

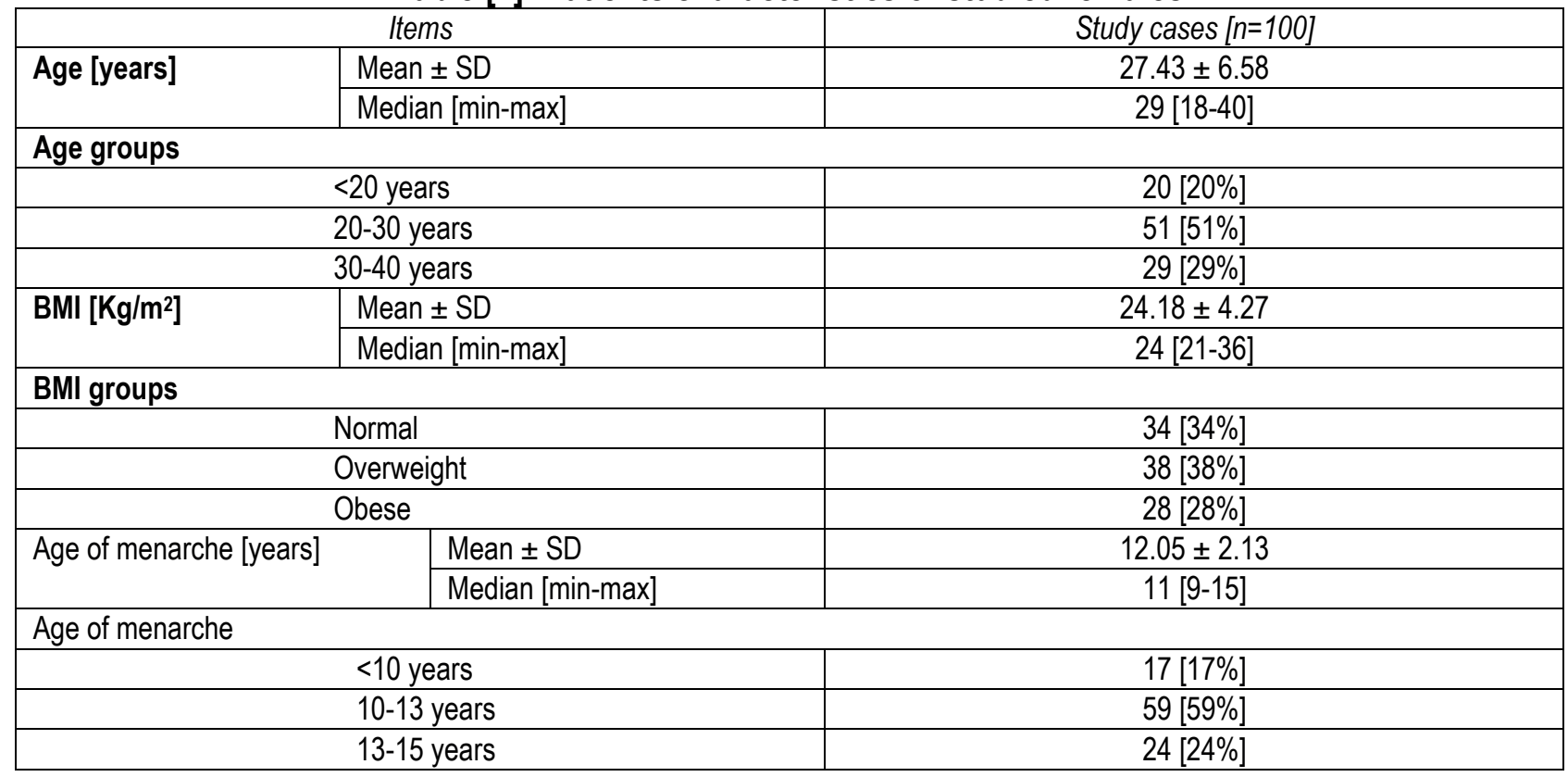

Table [2]: Recurrent pregnancy loss in the study cases

\begin{tabular}{|l|l|}
\hline Items & Study cases [n=100] \\
\hline Recurrent pregnancy loss [RPL] & $45[45 \%]$ \\
\hline Two & $55[55 \%]$ \\
\hline Three or more & \\
\hline
\end{tabular}


Table [3]: Hysteroscopic and ultrasound findings among studied cases

\begin{tabular}{|l|c|c|}
\hline \multicolumn{1}{|c|}{ Findings } & Hysteroscopy & 3D ultrasound \\
\hline Normal & $80[80 \%]$ & $83[83 \%]$ \\
\hline Endometrial polyp & $7[7 \%]$ & $6[6 \%]$ \\
\hline Submucous myoma & $3[3 \%]$ & $3[3 \%]$ \\
\hline Uterine septum & $6[6 \%]$ & $5[5 \%]$ \\
\hline Bicornuate uterus & $0[0 \%]$ & $1[1 \%]$ \\
\hline Uterine synechia & $4[4 \%]$ & $2[2 \%]$ \\
\hline
\end{tabular}

Table [4]: Measurement of agreement between the two techniques

\begin{tabular}{|l|c|c|c|}
\hline \multirow{2}{*}{ Kappa factor } & Value & Standard error & $P$-value \\
\cline { 2 - 4 } & 0.895 & 0.127 & $0.001^{*}$ \\
\hline
\end{tabular}

Table [5]: Distribution of the findings according to the number of RPL

\begin{tabular}{|c|c|c|c|c|}
\hline \multirow[t]{2}{*}{ Findings } & \multicolumn{2}{|c|}{ Hysteroscopy } & \multicolumn{2}{|c|}{ 3D ultrasound } \\
\hline & $\begin{array}{c}\text { Two RPL } \\
{[n=45]}\end{array}$ & $\geq$ Three RPL [n=55] & $\begin{array}{c}\text { Two RPL } \\
{[n=45]}\end{array}$ & $\begin{array}{c}\geq \text { Three RPL } \\
{[n=55]}\end{array}$ \\
\hline Normal & $38[84.4 \%]$ & $42[76.4 \%]$ & 34 [75.6\%] & $39[70.9 \%]$ \\
\hline Endometrial polyp & $3[6.7 \%]$ & $4[7.3 \%]$ & $2[4.4 \%]$ & $4[7.3 \%]$ \\
\hline Submucous myoma & $1[2.2 \%]$ & $2[3.6 \%]$ & $1[2.2 \%]$ & $2[3.6 \%]$ \\
\hline Uterine septum & $2[4.4 \%]$ & $4[7.3 \%]$ & $1[2.2 \%]$ & $4[7.3 \%]$ \\
\hline Bicornuate uterus & $0[0 \%]$ & $0[0 \%]$ & $0[0 \%]$ & $1[1.8 \%]$ \\
\hline Uterine synechia & $1[2.2 \%]$ & $3[5.5 \%]$ & $1[2.2 \%]$ & $1[1.8 \%]$ \\
\hline Test of significance & \multicolumn{2}{|c|}{$\begin{array}{l}{[t=1.495} \\
P=0.138\end{array}$} & \multicolumn{2}{|c|}{$\begin{array}{l}t=0.947 \\
P=0.327\end{array}$} \\
\hline
\end{tabular}

\section{DISUCSSION}

This study was conducted to assess the accuracy of the diagnosis of $3 \mathrm{D}$ ultrasonography compared to office hysteroscopy for the assessment of the uterine lesions in females complaining of RPL.

In the present study, the mean age of the cases was $27.43 \pm 6.58$ years with a range between 18 and 40 years. $20 \%$ of the cases were < age of 20 years, $51 \%$ of the cases were between 20 and 30 years and $29 \%$ of the cases were between 30 and 40 years.

Another study handling the same perspective also included a total of 100 cases with a mean age of 28 years [range, $20-39$ years] ${ }^{[7]}$.

In our study, hysteroscopy the following uterine findings were detected, Normal in $80 \%$ of the cases, endometrial polyp in $7 \%$, submucous myoma in $3 \%$ of the cases, uterine septum in $6 \%$ of the cases and uterine synechia in $4 \%$ of the cases.

By 3D ultrasound, the following uterine findings were detected, normal in $83 \%$ of the cases, endometrial polyp in 6\%, submucous myoma in 3\% of the cases, uterine septum in $5 \%$ of the cases, bicornuate uterus in 1\%and uterine synechia in $2 \%$ of the cases. In another study, seventy-nine patients were found to have Mullerian abnormalities where 59 patients had subseptate uteri, 11 had septate uteri, 5 had bicornuate uteri and 4 had unicornuate uteri. While only twenty-one patients had intracavitary lesions 14 polyp and 7 intracavitary fibroids [7].

In our study, there was a statistically significant association between the 2 procedures in detecting the uterine findings in cases of RPL [kappa factor 0.895 and $p=0.001]$. The best method of assessment of the cavity of the uterus is using hysteroscopy; on the other hand, it is minimally invasive and is typically carried out under anesthesia[8]. Furthermore, simultaneous hysteroscopy with laparoscopy is required as the best method in the diagnosis of the Müllerian anomalies [9].

[SIS] was introduced to replace hysteroscopy for accurate diagnosis of intracavitary lesions. However, it is still a minimally invasive procedure and associated with pain and/or discomfort. alternatively, pelvic MRI was regarded as a non-invasive tool to substitute the simultaneous hysteroscopy laparoscopy to detect the Müllerian anomalies [10]. but it is high-priced and not simply accessible [7, 11].

Also, the recently wide use of 3D TVs with the advantage of having the privilege of coronal view, accuracy, and pain-free, has revolutionized its place for evaluating uterine cavity and to be a good alternative to the previous gold standards [combined 
hysteroscopy with laparoscopy or the MRI] [7]. Additionally, several past studies documented that pelvic [MRI], [SIS] as well as hysterosalpingo contrast sonography are not higher or more accurate to 3D ultrasonography [11, 12]. In another study, as regards the comparison between three-dimensional ultrasonography and hysteroscopy in detecting intracavitary lesions compared to the histopathological study as a gold standard, 3DTVS showed low sensitivity and PPV [57.14\% and 75\% respectively] and reasonable specificity, NPV and diagnostic accuracy $97.77 \%, 95.11 \%$ and $93.50 \%$ respectively]. On the other hand, hysteroscopy showed a very high percentage $[95.45 \%$ for sensitivity, $100 \%$ for specificity and PPV, $99.44 \%$ for NPV, and $99.50 \%$ for Accuracy] [7].

Apirakviriya et al. reported also a similar result for the detection of the endometrial polyp by 3D TVs when putting side by side with hysteroscopy $[61.1 \%$ sensitivity, $91.5 \%$ specificity, and $83.1 \%$ diagnostic accuracy] that closely similar to the current result [13].

Fang et al. also documented the sensitivity of $65.6 \%$ and specificity of $89 \%$ for 3D-TVs in endometrial polyp detection [14].

Conclusion: Three-dimensional ultrasonography is the best tool for the diagnosis of different types of Mullerian anomalies. While on the other hand hysteroscopy is far better than the 3D US in the diagnosis of intracavitary lesions

\section{Financial and Non-Financial Relationships and Activities of Interest}

None

\section{REFERENCES}

1. El Hachem H, Crepaux V, May-Panloup P, Descamps $P$, Legendre G, Bouet P-E. Recurrent pregnancy loss: current perspectives. Int J Women's Health 2017; 9: 331. [DOI: 10.2147/IJWH.S100817].

2. Shahine L, Lathi R. Recurrent pregnancy loss: evaluation and treatment. Obstet Gynecol Clin 2015; 42 [1]: 117-134. [DOI: 10.1016/j.ogc.2014.10.002].

3. von Eye Corleta H. It is time to respect the American Society for Reproductive Medicine's definition of recurrent pregnancy loss. Fertil Steril. 2010; 94[4]: e61. [DOI: 10. 1016/j.fertnstert.2010.06.020].

4. Roepke ER, Christiansen OB, Hansson SR. Reliability of recurrent pregnancy loss diagnosis coding in the Swedish National Patient Register: a validation study. Clin Epidemiol. 2019; 11: 375. [DOI: 10.2147/CLEP. S199206].
5. Mathur KL, Srivastava S, Makwana S, Gupta A. Hysteroscopy: A retrospective study of 507 cases. Indian J Obstet Gynecol Res. 2019; 6[1]: 38-40. [DOI: 10.18231/ 2394-2754. 2019.0009].

6. Coccia ME, Rizzello F, Capezzuoli T, Spitaleri M, Riviello C. Recurrent pregnancy losses and gestational age are closely related: an observational cohort study on 759 pregnancy losses. Reprod Sci. 2015; 22[5]: 556-562. [DOI: 10.1177/1933719114553063].

7. Midan MF, Eid SM, ElSherbiny AM. Comparative study between three-dimensional ultrasonography and office hysteroscopy in infertile women with uterine cavity abnormalities. Middle East Fertil Soc J. 2017; 22 [4]: 329332. [DOI: 10.1016/j.mefs.2017.06.003].

8. Pundir J, Toukhy TE. Uterine cavity assessment prior to IVF. Women's health 2010; 6[6]: 841-848. [DOI: 10.2217/ whe.10.61].

9. Di Spiezio Sardo A, Di Carlo C, Minozzi S, Spinelli M, Pistotti V, Alviggi C, et al. Efficacy of hysteroscopy in improving reproductive outcomes of infertile couples: a systematic review and meta-analysis. Human Rep update 2016; 22[4]: 479-496. [DOI: 10.1093/humupd/dmw008].

10. El Huseiny AM, Ahmad RA, Sadek SM, Gouhar GK, Dawood HA. Role of three-dimensional ultrasound in the diagnosis of double uterine cavity anomalies and concordance with the laparoscopic and hysteroscopic diagnosis. Egyp J Radiol Nuclear Med. 2014; 45[2]: 555560. [DOI: 10.1016/j.ejrnm.2014.02.010].

11. Dewan KAAA, Hefeda MM, ElKholy DGE. Septate or bicornuate uterus: accuracy of three-dimensional transvaginal ultrasonography and pelvic magnetic resonance imaging. Egyp J Radiol Nuclear Med. 2014; 45[3]: 987-995. [DOI: 10.1016/j.ejrnm.2014.04.001].

12. Bermejo C, Martínez Ten P, Cantarero R, Diaz D, Pérez Pedregosa J, Barrón E, et al. Three-dimensional ultrasound in the diagnosis of Müllerian duct anomalies and concordance with magnetic resonance imaging. Ultrasound Obstet Gynecol. 2010; 35[5]: 593-601. [DOI: 10.1002/ uog.7551].

13. Apirakviriya C, Rungruxsirivorn T, Phupong V, Wisawasukmongchol W. Diagnostic accuracy of 3Dtransvaginal ultrasound in detecting uterine cavity abnormalities in infertile patients as compared with hysteroscopy. Eur J Obstet Gynecol Reprod Biol. 2016; 200: 24-28.[DOI: 10.1016/j.ejogrb.2016.01.023].

14. Fang L, Su Y, Guo Y, Sun Y. Value of 3-Dimensional and Power Doppler Sonography for Diagnosis of Endometrial Polyps. J Ultrasound Med. 2013; 32[2]: 247-255. [DOI: 10.7863/jum.2013.32.2.247]. 